\title{
СЛЕНГ НА ГАЗЕТНОЙ ПОЛОСЕ
}

\author{
Ольга Ермачкова, Марианна Фигедыова
}

\section{SLANG ON THE NEWSPAPER STRIP}

\author{
Olga lermachkova, Marianna Figedyová
}

\begin{abstract}
Резюме: Статья посвящена одному из самых динамичных процессов современного русского языка сленгизации. На материале российских печатных изданий рассматриваются причины внедрения сленговых слов в публицистический стиль, анализир уются функции такой лексики на газетной полосе.
\end{abstract}

Ключевые слова: сленг, русский язык, газетная полоса, функция, СМИ

\begin{abstract}
The article is devoted to slangization, which is one of the most dynamic processes of the modern Russian language. Based on material of Russian print media, the reasons for introducing slang words into a journalistic style are examined, and the functions of such vocabulary in a newspaper are analyzed.
\end{abstract}

Key words: slang, Russian, newspaper strip, function, media

DOI: $10.14712 / 9788076032088.2$

\section{Введение}

В последние десятилетия журналисты в борьбе за читательское внимание, в стремлении к проявлению своей творческой индивидуальности и даже своеобразному эпатажу обращаются к различным языковым единицам, особенно в заголовках публицистических текстов. Язык СМИ претерпевает все большие коррективы, в нем происходят эволюционные процессы становление новой лексической системности языка. Газетный текст отражает не только изменения, происходящие в социально-экономической и политической жизни, но и изменения в языке, находящиеся в поле зрения лингвистов. Е.А. Земская справедливо отмечает, что «язык современных газет может служить зеркалом современной российской жизни» (Земская 1996, 157). Одним из наиболее действенных рычагов манипуляции и эмоционального воздействия на газетной полосе является сленг - лексический пласт, к которому до сих пор весьма неоднозначное отношение.

Цель данного исследования - анализ проникновения сленга в современный публицистический стиль, а также рассмотрение причин внедрения и функциональных особенностей данной лексики.

\section{Проблематика сленгизации}

Язык - это живой организм, который постоянно пополняется новыми лексическими единицами вследствие ряда причин (технический прогресс, глобализация, демократизация общества, появление новых понятий и терминов, доминанция английского языка, 
гипертрофированная эмоциональность и свобода современного мира и т.п.) Наряду с литературным языком формировалась и все еще формируется особая группа слов, которой пользуются отдельные слои общества (молодежь, заключенные, программисты, врачи и др.) В наше время этот пласт лексики с периферии все чаще выходит на первый план, поэтому внимание лингвистов к этому феномену неуклонно растет. Специалисты пытаются изучить природу данного явления, дать более конкретные определения, разграничить смежные понятия арго - жаргон - сленг, создать соответствующие словари.

Сленгу посвящено множество работ и их количество постоянно увеличивается. В сленгологии классическим примером служит публикация В. Дж. Бурка «Литература о сленге», в которой обобщаются исследования по сленгу за последние сто лет (Бурк 1939). В этой работе имеются как отрицательные оценки сленга: «Невежество пользуется сленгом, так как невежество копирует праздность»; “Фамильярность оскорбительна, а сленг фамильярен. Давайте же не допускать его в наш язык», так и положительные: “Сленг - живая метафора. Это заранее отчеканенное остроумие»; “Сленг - это поистине сконцентрированная энергия жизни» (цит. по Липатов 2010, 50-51).

В русской лингвистике сленг начали изучать еще в 30-х годах XX века (В.В. Виноградов, А.М. Селищев, Б.А. Ларин, Е.Д. Поливанов и др.). На данный момент свет увидел ряд монографий («Введение в изучение слэнга - основного компонента английского просторечия» В. А. Хомякова (1971), «Сленг как проблема социолектики» А.Т. Липатова (2010)), словарей («Словарь молодежных сленгов» М.А. Грачева, А.И. Гурова (1989), «Словарь молодежного жаргона» И.А. Стернина (1992), «Словарь русского сленга» И. Юганова, Ф. Югановой (1997), «Толковый словарь молодежного сленга: Слова, непонятные взрослым» Т.Г. Никитиной (2003), «Толковый словарь русского сленга» В.С. Елистратова (2010) и др.). Вплоть до 90-х гг. заниматься данным явлением считалось зазорным, так как лингвисты не воспринимали его всерьез.

У термина сленг существует множество определений. Найти общий знаменатель очень непросто из-за диапазона самого термина и его изменчивого характера. Одним из первых проблематикой сленга занимался В.А. Хомяков, который утверждал, что «...под термином слэнг понимают совершенно различные явления, так как слэнг обычно сводят: к «низкому, вульгарному языку», то есть к всевозможным грубым, иногда попросту непристойным выражениям; к различным жаргонам, как социально-профессиональным, так и секретным и полусекретным арго преступного мира и полусвета; особый нелитературный разговорный язык со своеобразным вокабуляром» (Хомяков 1971, 33-34).

Русские словари включают термин сленг уже с 60-х годов XX века. Так в «Словаре лингвистических терминов» О.С. Ахмановой даны два значения сленга: 1. Разговорный вариант профессиональной речи; 2. Элементы разговорного варианта той или другой профессиональной или социальной группы, которые, проникая в литературный язык или вообще в речь людей, не имеющих прямого отношения к данной группе лиц, приобретают в этих разновидностях языка особую эмоционально-экспрессивную окраску (Ахманова 1966, 419).

Эталонным определением термина сленг в русском языкознании стала дефиниция В.А. Хомякова: «Сленг - это относительно устойчивый для определенного периода, широко употребительный, стилистически маркированный (сниженный) лексический пласт (имена существительные, прилагательные и глаголы, обозначающие бытовые явления, предметы, процессы и признаки); компонент экспрессивного просторечия, входящего в литературный язык, весьма неоднородный по своим истокам, степени приближения к литературному стандарту, обладающий пейоративной экспрессией» (Хомяков 1980, 43-44). 
Среди определений последних десятилетий самыми емкими, нам кажутся, определение Т.В. Жеребило: «Социальный диалект, групповой язык, характеризующийся экспрессивной направленностью» (Жеребило 2010, 332) и Г.Ю. Алимовой: “... совокупность постоянно трансформирующихся языковых средств высокой экспрессивной силы, которые используются в общении молодыми людьми, состоящими в фамильярных, дружеских отношениях» (Алимова 2017, 607).

На наш взгляд, ключевыми моментами при определении сленга являются экспрессивность и социальная группа.

\section{Сленг на страницах СМИ}

В современном мире СМИ являются источником новых слов и выражений. Все чаще на первых полосах газет пестреют заголовки с просторечными или сленговыми словами, привлекая внимание, вызывая как негодование, так и восторг читателей. Н.Б. Егошина $(2013,13)$ считает, что авторы прибегают к сленгу в СМИ, преследуя определенные цели: формирование и поддержание имиджа; стремление к неординарности; завоевание доверия аудитории, особенно в молодежных программах и рекламе, направленной на молодых людей; оказание воздействия на сознание человека. Последняя, нам кажется, основополагающей функцией сленга в СМИ.

В данной работе мы будем анализировать сленговые слова и выражения в статьях «Комсомольской правды» (КП) за 2019-2020 гг.:

- Не впечатляют подобные траблы, сначала лопаты а после че, грабли? (КП, 7.06.19). Трабл - неудача, неприятность, сложная проблема (Никитина 2003, 585).

- В поисках богатств он в нищенском феврале 1992 года наскреб в резервном фонде 1,5 млн «зеленых» (КП, 15.12.19); Дальше органайзер собираются продавать дороже, примерно за 150-180 «зеленых» (КП, 3.3.19). Зеленый - доллар США (Никитина 2003, 214).

- Это соотношение зависит от того, насколько кучеряво живем (КП, 15.01.19). Кучеряво - хорошо, часто в смысле богато, роскошно, престижно (Словарь молодежного слэнга, онлайн).

- ... если прикидывать грубо, обходятся миллиона в полтора-два (КП, 15.01.19); Вы написали о пришельцах, а кто-то прикидывает, закладываете ли вы за воротник (КП, 3.10.19); Так или иначе многие из нас прикидывают, сколько стоит их квартира... (КП, 19.3.19). Прикидывать - понимать, принимать к сведению, представлять себе чтолибо (Никитина 2003, 468).

- Какие рубли рулят (КП, 15.01.19). Рулить - руководить чем-либо (Никитина 2003, 509).

- Но у работодателей свои резоны (КП, 11.03.19); Еще бы, Питер сидит на всей мировой информации о пришельцах, есть резон засекретиться (КП, 3.10.19). Резон смысл, выгода (Словарь молодежного слэнга, онлайн).

- Я не компьютеры делаю и не гаджеты, а фарш и колбасу... (КП, 11.03.19); В наше время книги заменены гаджетами (КП, 28.6.19). Гаджет - несамостоятельное присоединяемое техническое устройство (Словарь молодежного слэнга, онлайн).

- Но, оказывается, вполне можно припахать смартфон к экономии (КП, 17.03.19). Припахать - привлечь кого-либо к каким-либо работам, заставить делать что-либо (Никитина 2003, 471). 
- Несут с экранов и в разных СМИ все более ломовую чушь (КП, 27.03.19). Ломовой напористый, решительный (Никитина 2003, 317).

- Бонусы - это то же самое, что откаты учиновников, только называются мягче (КП, 19.03.19). Откат - доля прибыли; получение доли прибыли (Никитина 2003, 406).

- Потому что они прекрасно живут, плодятся, даже имеют преимущество, потому что ничем не заморачиваются (КП, 7.11.19). Заморочиться -ответственно и серьезно выполнить какую-либо работу, которую иногда не очень хочется выполнять (Никитина 2003, 195).

- Хорошо, когда ребенок добр, когда он не сравнивает себя с другими детьми - кто круче (КП, 28.6.19); ... достаточно ли я крут в их глазах? (КП, 28.6.19). Крутой преуспевающий, удачливый, респектабельный; впечатляющий, яркий, оригинальный; отличный, прекрасный, заслуживающий одобрения (Никитина 2003, 288).

- Ученые доказали: «тупить» в интернете на работе - это полезно, главное не делать это слишком долго (КП, 12.5.20). Тупить - не понимать чего-либо. (Никитина 2003, 593).

- Если говоришь, что просто хочешь перекусить, начинают ломаться (КП, 26.3.19). Ломаться - притворно отказываться, кокетничать, торговаться; часто об отношениях между девушками и парнями (Словарь молодежного слэнга, онлайн).

- Интересно, если фрики в самом деле пойдут итурмовать Базу 51 и попадут под пули...? (КП, 23.9.19). Фрик - красиво, модно одетый человек (Никитина 2003, 638).

- Kстати, в продвинутых кофейнях, например в Черкасской области, посетителям предлагают трубочки из настоящей соломы (КП, 30.11.19). Продвинутый - серьезно занимающийся чем-либо, знающий что-либо лучше других (Никитина 2003, 477).

- Девушки часто жалуются, что на сайтах знакомств им попадаются жадные мужчины, сексуальные маньяки или страшные парни, присылающие левые фото (КП, 26.3.19). Левый - ненастоящий, фальсифицированный (Никитина 2003, 305).

- Мы в редакции, помню, тоже угорали: это же надо докатиться до такой степени дебилизма! (КП, 18.2.20). Угорать - смеяться (долго, до изнеможения) (Никитина 2003, 603).

- Да вам с этим ЕГЭ такую лафу сделали, что дальше некуда! (КП, 8.2.20). Лафа счастье, удача; беззаботная жизнь (Никитина 2003, 304).

- Что за фигня, у меня другие планы: директор ДК отменил спектакль "Анна Каренина», устроив вместо него дискотеку (КП, 7.12.19); Шнуров высказался о пожаре в Нотр-Дам-де-Пари: «Все это фигня» (КП, 16.4.19). Фигня - ерунда, чушь (Никитина 2003, 629).

- Наверное, был я бухой: Почему концерт группы "Ленинград» в Кишиневе - лучший концерт, который когда-либо был в столице (КП, 3.9.19). Бухой - пьяный (Никитина 2003, 62).

- И вот торжественный день: во время батла вы приготовите свое фирменное блюдо (КП, 15.5.20); Хип-хоп батл и фристайл разогрели городские улицы (КП, 5.8.19). Батл соревнования исполнителей брейк-данса (Никитина 2003, 64).

- Как завещал нам Цой в конце двадцатого века, конец света - неплохой повод, чтоб замутить дискотеку! (КП, 22.4.20). Замутить -организовать что-либо (Никитина 2003, 196). 
- Типо эти заморочки... чисто местная проблема (КП, 18.2.20). Заморочка -навязчивая идея, странность поведения (Никитина 2003, 196).

- Невоспитанные жлобы или приветливые красавцы (КП, 18.7.19). Жлоб - человек с низким интеллектуальным уровнем, ограниченный, лишенный вкуса, скупой и т.п. (Никитина 2003, 167).

- Как ребенку смотреть телевизор: Дольше 30 минут не зависать, на 3 метра не приближаться (КП, 14.1.20). Зависать - оставаться где-либо; бездельничать, бездействовать; увиливать от работы; сильно увлекаться чем-либо, быть поклонником (Никитина 2003, 176).

- Когда девушка поняла свой промах, то решила попытаться «закадрить» водителя во второй раз. (КП, 13.9.19). Кадрить - пытаться понравиться кому-либо (Никитина 2003, 226).

Все чаще сленговые слова и выражения появляются в заголовках статей:

- Положи мне денег на трубу (КП 29.08.19). Труба - сотовый (мобильный) телефон (Никитина 2003, 589).

- Скинь фото на мыло (КП 29.08.19). Мыло - почта (Никитина 2003, 357).

- Как побороть левак (КП 12.7.19). Левак - что-либо низкого качества (Никитина 2003, 305).

- Смотри по ящику (КП 19.04.19). Ящик - телевизор (Никитина 2003, 723).

- Тачки счет любят (КП, 15.01.19); Тачка на прокачку (КП 19.03.20); Тачка больших возможностей (КП, 22.5.19). Тачка - легковая автомашина (Никитина 2003, 571).

- Пир во время коронавируса: молодежь устроила дикую тусу в центре Новосибирска» (КП, 24.5.20). Туса - вечеринка, увеселительное мероприятие (Никитина 2003, 594). В данном заголовке отмечаем аллюзию на произведение А.С. Пушкина «Пир во время чумы».

- На западло и суда нет (КП, 18.5.20). Западло - унизительно, не соответствует положению, статусу; плохо, не стоит; неприятно, не нравится; невезение, неудача; выражение досады, раздражения, гнева (Никитина 2003, 197-198).

- Недолайканные и недобаненные (КП, 7.10.19). Лайкать - любить кого-либо, что-либо (Никитина 2003, 302). Бан (англ. ban) - запрещать, объявлять вне закона.

\section{Выводы}

В статьях «Комсомольской правды» за последние годы были обнаружены сленговые слова и выражения, большинство из которых имеют английское происхождение (трабл, батл, гаджет, резон, бойрренд, лузер, хейтер, фрик и др.). Слово гаджет было использовано многократно с целью экономии речи. Являясь емким, оно способно заменить целое выражение (высокотехнологичные устройства) и выполнить компрессивную функцию. Остальные же "сленгизмы-чужестранцы» имеют русские аналоги и лишь отдают дань моде на все зарубежное (трабл - неприятность; лузер - неудачник; хейтер - ненавистник, критикан; лайкать нравиться, любить), выполняя порой деструктивную функцию. Многие англицизмы, проникая в русский сленг, подчиняются морфологическим правилам русского языка, начинают проявлять 
видовое значение (спикать - наспикаться), образуют новые формы грамматического рода и числа (френд - френда-френды) и т.п.

Стоит также заметить, что исконно русский сленг на газетной полосе не уступает иностранному (угорать, припахивать, тупить, кадрить, заморачиваться и др.). Применяя иноязычный сленг, авторы рискуют столкнуться с недопониманием контекста старшим поколением.

Рассматривая сленговые выражения в публицистическом тексте, мы заметили, что чаще всего данный лексический пласт присущ статьям общественно-социальной направленности (напр., проблемы молодежи, детей, подростков, наркоманов, алкоголиков и др.). В данном контексте сленгизмы реализуют идентифицирующую функцию - могут четче описать представителя определенной группы, его характер и внешний вид (напр., жлоб, фрик, продвинутый), поведение (напр., зависать, тусить, ломаться, мутить, кадрить).

Сленг, являясь в какой-то степени языком народа, привлекает читателей своей простотой, ясностью и доступностью (ломовой, крутой, фиолетово, мыло, труба). Помогая устанавливать контакт между автором и рецепиентом, сленг реализует апеллятивную функцию.

Первостепенными, на наш взгляд, функциями сленга на газетной полосе являются экспрессивная и аттрактивная функции (напр., Какие рубли рулят; Тачки на прокачку; Как побороть левак). Какие именно эмоции вызовут подобные заголовки журналисты могут только догадываться, а вот на привлечение внимания к своей публикации они могут рассчитывать.

Не менее важной функцией представляется нам характерологическая функция сленга, так как посредством языкового материала автор репрезентирует себя, пытается сблизиться с читателем. Нередко передавая прямую речь эпатажных людей, журналисты вынуждены прибегать к сленгу (напр., высказывания музыканта Сергея Шнурова, актера Михаила Ефремова, политика Владимира Жириновского и др.).

В ходе данного исследования мы также отметили вкрапления сленговых слов в прецедентные тексты, например: Тачки счет любят (ср. Деньги/денежки счет любят - цитата из сказки «Золотой ключик» А. Толстого); Тачка больших возможностей (ср. Город/страна больших возможностей); На западло и суда нет (ср. На нет и суда нет). Используя прецедентный материал, авторы статей должны учитывать, что такие «ассоциации бывают понятны среднему носителю языка только в том случае, когда эти произведения, их автор и персонажи ему знакомы, т.е. когда реципиент обладает достаточными фоновыми знаниями» (Корина, Билчикова 2017, 39).

Анализируя язык газетной полосы, мы также обнаружили окказиональные слова, образованные на основе сленга (напр., Недолайканные и недобаненные). Это свидетельствует о языкотворческой функции сленга.

Еще одной особенностью, по нашему мнению, является активное образование сленговых слов от имен собственных (напр., петросянить - неудачно шутить, образовано от фамилии Петросян, кепка-жириновка - образовано от фамилии Жириновский); на фонетическом сходстве (напр., Аська-ICQ; Емеля - адрес e-mail; Бухара - бухать, напиться; Валя - валюта; Егор - (англ. error) сбой, ошибка и др.).

В русском языкознании сленг противопоставляется литературному языку $и$ подразделяется на общий и специальный. В случае с газетным текстом мы имеем дело с общим сленгом, рассчитанным на узнаваемость всем социумом или его большей частью.

Сленг в публицистическом тексте - поиск авторами новых выразительных средств в период всесказанности. Языковые эксперименты с данным лексическим пластом - 
последствие глобализации, демократизации общества, американизации, изменений стилевых норм и дань языковой моде.

\section{Использованная литература/ References}

\section{Печатные источники:}

АЛИМОВА, Г.Ю. (2017): Молодежный сленг и разговорная речь в современной лингвистике. In Молодой ученый. 2017, №12 (146). с. 606-608. ISSN 2072-0297.

AХMAHОВА, О.С. (1966): Словарь лингвистических терминов. М.: Советская энциклопедия, 1966. 608 с. Без ISBN.

ЕГОШИНА, Н.Б. (2013): Сленг в СМИ: лексикографический аспект (на материале одноязычных и двуязычных словарей): автореферат диссертации на соискание уч. степени к.ф.н. Иваново: типография Ивановского энергетического колледжа, 2013. 24 с.

ЖЕРЕБИЛО, Т.В. (2010): Словарь лингвистических терминов. Изд. 5-е. Назрань: ООО «Пилигрим», 2010. 486 c. ISBN 978-5-98993-133-0.

ЗЕМСКАЯ, Е.А. (1996): Русский язык конца ХХ столетия (1985-1995). М.: Языки русской культуры, 1996. 481 c. ISBN: 5-7859-0001-7

КОРИНА, Н., БИЛчИкОВА, М. (2017): Цитатные ассоциации как вид интертекстуальной связи. In Slavica Nitriensia : časopis pre výskum slovanských filológií. Вып. 6, № 2. Нитра: УКФ, 2017. с. 34-55. ISSN 1338-7464. лиПАТОВ, А.Т. (2010): Сленг как проблема сочиолектики. М.: ЭЛПИС. 2010. 319 с. ISBN: 978-5-7712-03829.

никИТИНА, Т.Г. (2003): Толковый словарь молодежного сленга: Слова, непонятные взрослым. М.: Астрель: АСТ, 2003. 736 с. ISBN 5-17-015420-8, ISBN 5-271-05053-Х.

ХОМЯКОВ, В.А. (1971): Введение в изучение слэнга - основного компонента английского просторечия. Вологда: Областная типография. 1971. 104 с. Без ISBN.

ХОМяКОВ, В.А. (1980): Нестандартная лексика в структуре английского языка национального периода: автореф. ...канд. филол. наук. Л., 1980. 39 с. Без ISBN.

\section{Онлайн-источники:}

СЛОВАРЬ МОЛОДЕЖНОГО СЛЭНГА (онлайн): СЛоварь молодежного слэнга [онлайн]. Режим доступа: https://teenslang.su/ [дата обращения: 02.06.2020].

СЛОВАРЬ МОЛОДЕЖНОГО СЛЭНГА (онлайн): СЛоварь молодежного слэнга [онлайн]. Режим доступа: http://www.onlinedics.ru/slovar/slang.html [дата обращения: 02.06.2020].

ДАННАЯ СТАТЬЯ ПОДГОТОВЛЕНА В РAMKAX ПРОЕКTA KEGA Č. 021UCM-4/2020 S NÁZVOM TVORBA UČEBNíC PRE RUSKOSLOVENSKÉ SEKCIE BILINGVÁLNYCH A SLOVANSKÝCH GYMNÁZIÍ.

\section{Профиль автора:}

Ольга Евгеньевна Ермачкова, старший преподаватель, к.ф.н.

Научные интересы: динамические процессы в современном русском языке, лингвокультурология e-mail: olga.iermachkova@ucm.sk

Место работы: Университет Св. Кирилла и Мефодия в Трнаве, Трнава, пл. Й. Герду 2, 917 01, Словакия

\section{Author's profile:}

Mgr. Olga lermachkova, PhD.

Research interests: dynamic processes in the modern Russian language, linguoculturology

e-mail: olga.iermachkova@ucm.sk

Place of work: University of Ss. Cyril and Methodius in Trnava, J. Herdu 2, 917 01, Trnava, Slovakia 


\section{Профиль автора:}

Марианна Фигедыова, старший преподаватель, к.ф.н.

Научные интересы: лингвокультурология, литературоведение, современный русский язык e-mail: marianna.figedyova@ucm.sk

Место работы: Университет Св. Кирилла и Мефодия в Трнаве, Трнава, пл. Й. Герду 2, 917 01, Словакия

\section{Author's profile:}

PaeDr. Marianna Figedyová, PhD.

Research interests: linguoculturology, literary criticism, modern Russian language

e-mail: marianna.figedyova@ucm.sk

Place of work: University of Ss. Cyril and Methodius in Trnava, J. Herdu 2, 917 01, Trnava, Slovakia 